\title{
URBANIDADE NOS BAIXIOS DE VIADUTOS Possibilidades e transformações em áreas intersticiais
}

\author{
Urbanity underpass viaducts \\ Possibilities and transformations in interstitial areas
}

Camañes Guillén, Maria Isabel;

Faculdade de Arquitetura e Urbanismo,Universidade Presbiteriana Mackenzie de São Paulo isabelcamanes5@gmail.com

\begin{abstract}
RESUMO
O presente artigo tem a intenção de observar os espaços inferiores resultantes de implantações de vias urbanas, os baixios de viadutos, na cidade de São Paulo. Estes, tidos como desqualificados, são objetivo da investigação, com o objetivo de estabelecer a hipótese de que neles pode haver urbanidade. Neste sentido, buscamos articular conceitos ligados à relação entre forma urbana e urbanidade, verificando como se dão as estratégias de ocupação em quatro viadutos na cidade. O artigo busca inicialmente articular as noções de urbanidade e a situação dos viadutos na cidade de São Paulo, evidenciando a dimensão destes territórios na cidade. Em etapas seguintes são elencados caminhos possíveis para evidenciar a urbanidade nestes espaços e relacionar com os atributos de morfologia e forma urbana dos territórios a que pertencem. Nas conclusões, pode-se verificar algumas relações entre forma, morfologia e ocupação destes lugares, que podem estabelecer parâmetros para quantificar ou qualificar os níveis de urbanidade.
\end{abstract}

Palavras chave: Baixios de viadutos, urbanidade, infraestruturas de mobilidade Bloco temático: Espaço público e projeto urbano na metrópole contemporânea

\begin{abstract}
This article intends to observe the inferior spaces resulting from urban pathway deployments, the underpass viaducts, in the city of São Paulo. These, taken as disqualified, are the objective of the investigation, with the aim of establishing the hypothesis that there may be urbanity. In this sense, it seems to articulate concepts related to the relationship between urban form and urbanity. How are the strategies of occupation given in four viaducts in the city? The article initially looks for the notions of urbanity and the situation of the viaducts, evidencing the territories sizes in the city of São Paulo. In the following stages, it's possible be listed to evidence of the urbanity in these spaces and relate to the attributes of morphology and urban form. In the conclusions, it can be verified some relationships between form, morphology and occupation with parameters to quantify or qualify the levels of urbanity.
\end{abstract}

Keywords: Underpass viaducts, urbanity, mobility infrastructures.

Topic: Public space and Urban project in the contemporary metropolis. 


\section{Introdução}

A Urbanidade dos espaços reflete a qualidade de relações que se estabelecem entre a cidade e as pessoas, reflete o "caráter do urbano", iniciando pelos "espaços hospitaleiros" e se estende "ao conjunto de qualidades, boas ou más, que constituem as cidades" (Aguiar, 2012). Nesta análise dos baixios de viadutos da cidade de São Paulo, verificando em alguns casos abordados questões referentes à utilização e características formais do entorno. Na formação da cidade de São Paulo, diferentes períodos são percebidos e podem ser relacionados com as vias da cidade. A vida urbana e os espaços públicos que, em determinado momento histórico, cederam seus espaços para abrigar os viadutos, desenvolvem processos de transformação e estabelecem novas dinâmicas pautadas no uso do automóvel.

O interesse pelos espaços residuais sob os viadutos urbanos surge com a constatação de uma tipologia urbana, que mesmo com uma característica genérica, e situando-se à margem do projeto arquitetônico, ainda pode acolher inúmeras possibilidades de usos e transformações. De acordo com o pensamento de Manuel de Solà Morales (2008), em sua conferência sobre "A urbanidade da arquitetura", a urbanidade está na materialidade das coisas, mesmo que elas sejam desprovidas de uso e ocupação, já para Romulo Krafta, (2012), "a urbanidade na forma urbana adiciona um aspecto ausente ou assumido como não problemático".

Em outras abordagens, Krafta (2012), entende a urbanidade como historicamente produzida, uma produção de "urbanidades amalgamadas" no tempo, por meio do espaço urbano: "o exame das características de cada objeto à luz de suas pré-existências. De acordo com este olhar, apoiado nas pré-existências do território, o artigo busca uma tentativa teórica de abarcar o fenômeno da urbanidade, com base na Morfogênese de Conzen (Kropf, 2004) por meio das descrições de agenciamento do espaço urbano, associadas a momentos históricos e possivelmente indutoras de formas urbanas particulares.

O âmbito do trabalho, se dá por meio de um referencial documental obtido por meio de revisão bibliográfica e coleta de dados e imagens em meios digitais. A análise parte da eleição de seis casos distintos na cidade de São Paulo, escolhidos de um universo de análise maior em desenvolvimento, desenvolvidos a partir de uma metodologia de análise comparativa, onde são verificados os critérios de localização geográfica, tipologia edilícia do entorno e estratégias de ocupação.

\section{São Paulo: Cidade dos Viadutos}

No século XVIII, foram surgindo as primeiras pontes, que cruzavam os rios Anhangabaú, Tietê, Pinheiros e Tamanduateí (figura 01). A implantação das primeiras ferrovias no século XIX seccionou diversas rotas com cruzamentos em nível, locais de frequentes acidentes. A intensificação dos fluxos de pessoas e veículos nestes cruzamentos com as ferrovias tornou necessária a construção dos primeiros viadutos. Posteriormente, na segunda metade do século $\mathrm{XX}$, a cidade experimentou seu maior ciclo de desenvolvimento, com explosão econômica, demográfica e do uso do automóvel como meio de locomoção, agravando os conflitos de mobilidade e exigindo grandes investimentos em soluções mais complexas para fazer frente aos crescentes congestionamentos. 


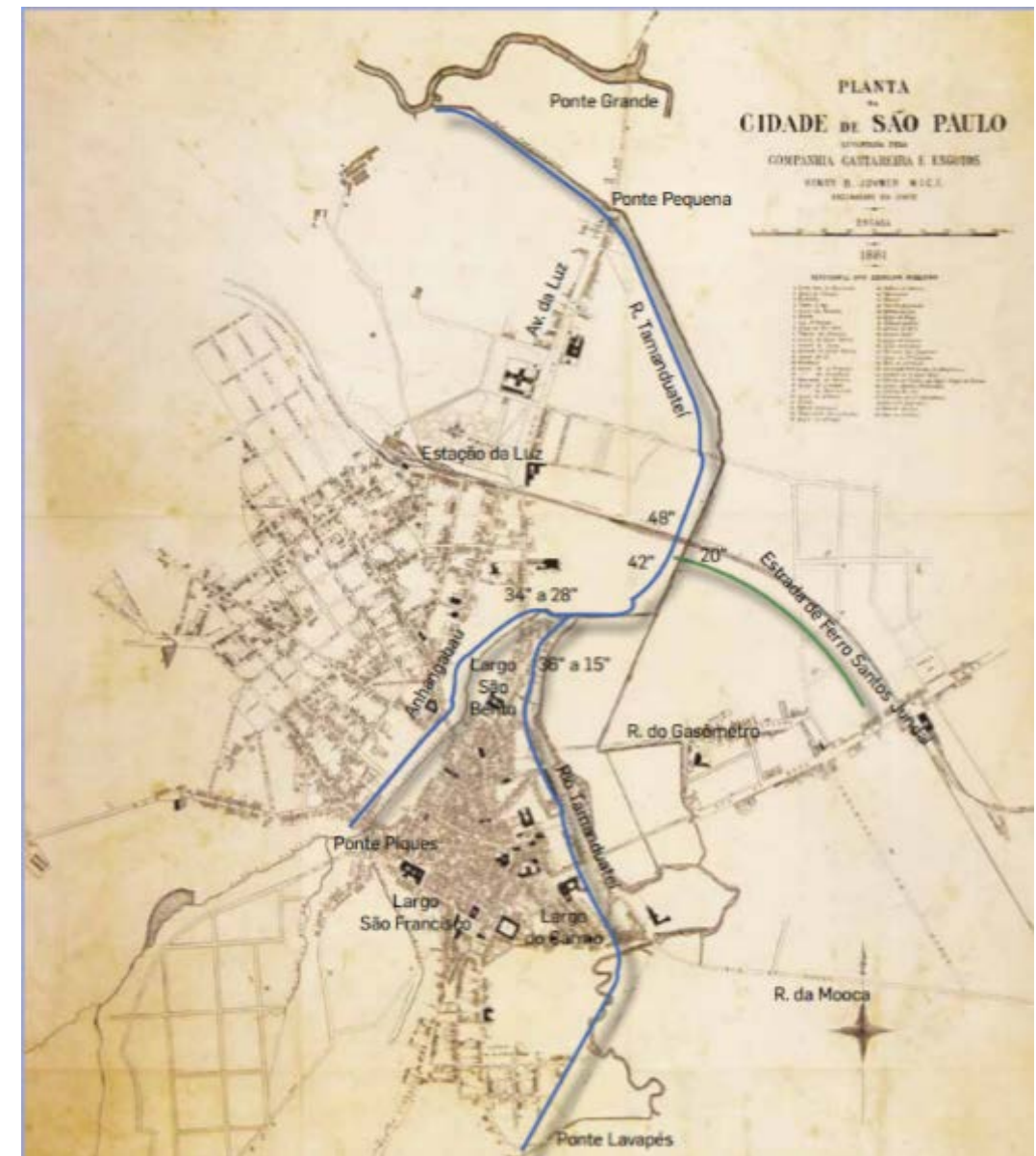

Fig. 01 Mapa histórico da cidade de São Paulo, em 1881. Destaque para os rios Tamanduateí, Anhangabaú e a Pontes Lavapés(sul), Ponte Piques (centro-oeste), Ponte Pequena e Ponte Grande (norte, cruzando rio Tietê). Fonte: (Oseki, 1992)

Os primeiros planos desenvolvidos pelo poder público datam da década de 1920, o "Plano de Avenidas", apresentado no ano de 1930, direcionou todas as ações públicas referentes à mobilidade urbana ao longo das décadas subsequentes. Neste plano um esquema de vias radiais e perimetrais organizadas em torno do centro, foi elaborado e sedimentou conceitos decisivos como a priorização do automóvel e a destinação viária dos fundos de vale (figura 02), com a canalização das águas dos riachos, córregos e rios, privatização da água que até então era um bem público e desocupação da população que habitava as várzeas.

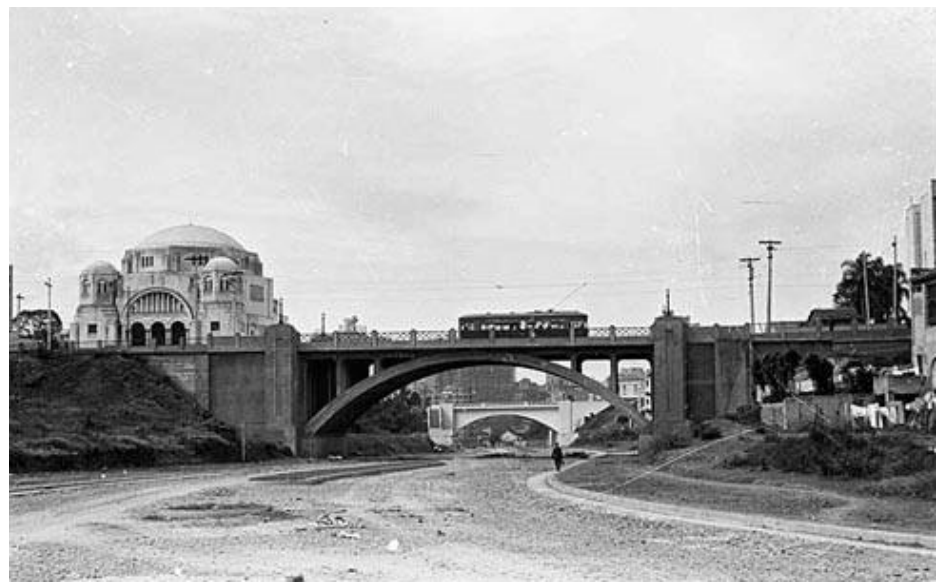

Fig. 02 Ponte Paraíso, sobre a Av. 23 de Maio (fundo de vale), canalizada. Fonte: Museu da cidade de São Paulo (autor desconhecido) 
As avenidas construídas sobre os vales dos rios canalizados, deram vazão à demanda da mobilidade rodoviária paulistana, a partir dos anos de 1950, transformando o território e estabelecendo outras tantas transposições e passagens, aumentando a quantidade de pontes e viadutos da cidade, necessários para vencer um território repleto de barreiras naturais e estabelecendo padrões de desenvolvimento viário urbano na cidade.

Atualmente, a cidade de São Paulo contabiliza 168 viadutos e 45 pontes (figura 03), administrados pelo Município. No entendimento destas passagens subterrâneas, presentes no universo da cidade de São Paulo, identificamos uma habilidade subjetiva e um caráter de resistência à normativa imposta ao espaço público, revelando uma diversidade e uma potencialidade projetual, assim como uma constante adaptação destes lugares no decorrer no tempo, permitindo a copresença de diferentes objetos e indivíduos (Krafta, apud Aguiar, 2012).

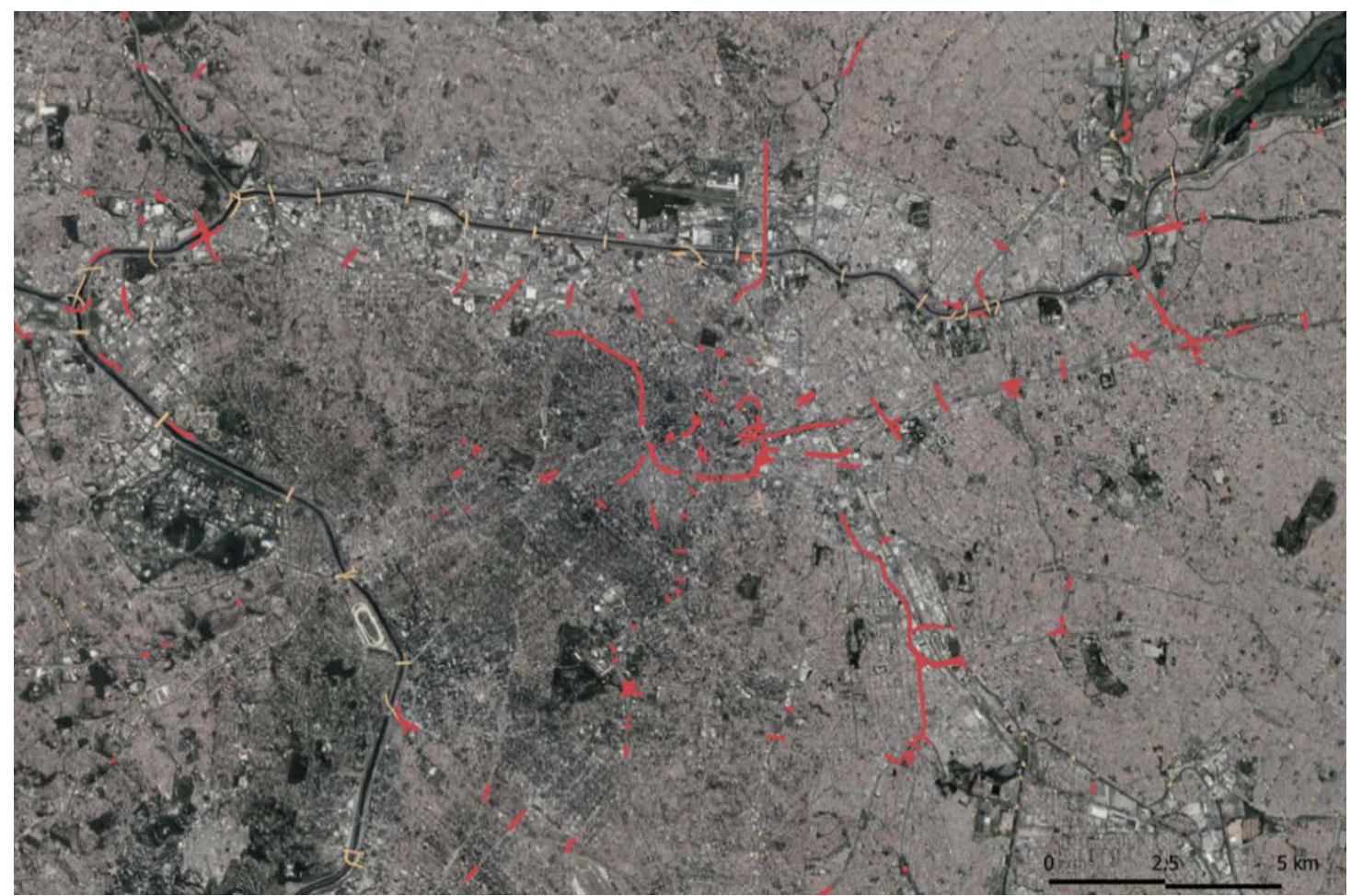

Fig. 03 Mapa com localização das Pontes e Viadutos de São Paulo. (Elaborado pela autora). Em vermelho: Viadutos. Em laranja: Pontes.

\section{Urbanidade nos interstícios}

A urbanidade dos espaços nas cidades tem relação com as relações que se estabelecem entre o ser humano e as coisas que configuram o lugar. De acordo com Henri Lefebvre (1974) os "espaços relacionais" são entendidos como um cenário de neutralidade, com o objetivo de desenvolver atividades, de acordo com sua teoria, os espaços eram construídos constantemente, evidenciando em sua história manifestações do imaginário e emocional das pessoas que ali viviam.

Nos espaços resultantes dos interstícios das infraestruturas viárias, existe a possibilidade do estabelecimento de vínculos, uma vez que são espaços públicos pertencentes à cidade e se transformam de acordo com o uso e permanência das pessoas. Comparando-os ao que Foucault (1984) denomina de espaços reais, onde dissolve-se a noção de um lugar ao qual se acopla uma identidade única e uma função exclusiva, este espaçolugar projetado e construído segundo lógicas funcionais estritas comporta múltiplos estratos superpostos ou 
sobrepostos e temporalidades cambiantes, redesenhando os limites, os recortes e as temporalidades usuais dos espaços urbanos. (Guatelli, 2012).

A urbanidade, tanto em sua escala local arquitetônica quanto na escala global da articulação com o entorno próximo e a cidade, se manifesta tanto para Jacobs (1960), quanto para Lynch (1961) na percepção e apreensão dos elementos fixos e móveis e, em especial, as pessoas e as atividades que desenvolvem. A perda da diversidade das novas urbanizações, manifesta por Jacobs (1960) é entendida de acordo com uma relação entre as urbanizações produzidas em grande escala e aquelas ditas de crescimento natural. Esta diversidade possui um caráter pautado nas dimensões arquitetônica, de tipologia de edificação, de espaços públicos e de atividades, manifestos por presenças sociais diferentes, tanto em termos econômicos quanto étnicos. (Aguiar, 2012).

Para Solà Morales, adepto das teorias de Lefebvre, o projeto urbano se desenvolve em uma sequência de elementos e episódios concretos que relacionam pessoas e cidade, assim como uma relação entre a materialidade, por meio do que Clúa (2017) chama de "pele da cidade", que seria a superfície onde as relações sociais e físicas se desenvolvem. Visando esta dimensão da "urbanidade como efervescência do urbano" (Netto, apud Aguiar, 2012), verificamos por meio da Tab.01, as relações entre espaços e atos.

\begin{tabular}{|l|l|l|}
\hline DIMENSÃO & SOCIAL & ESPACIAL \\
\hline FENOMENOLÓGICA & Co-presença/Encontro & $\begin{array}{l}\text { Rua, Espaço Público, Encontro de } \\
\text { diferentes }\end{array}$ \\
\hline COMUNICATIVA & Autores em interação & As modalidades, o lugar, a arquitetura \\
\hline ONTOLÓGICA & Cognição, conexões, referência ato-espaço-ato & $\begin{array}{l}\text { A rede de espaços públicos, lugares e } \\
\text { edificações }\end{array}$ \\
\hline
\end{tabular}

Tab. 01 Dimensões da Urbanidade. (Netto, apud Aguiar, 2012)

De acordo Romulo Krafta (2012) dentre as possíveis formas de aferir urbanidade existe a necessidade de aferir grau de intensidade, grau de pertencimento e padrões dominantes. A observação que toma a urbanidade como fator que agrega comportamentos individuais socialmente aceitáveis, sem valoração, porém com manifestação de diferentes padrões, seria a mais efetiva. A urbanidade da forma, ainda segundo Krafta (2012), pode assumir pelo menos três padrões distintos: por homogeneidade genérica, por diversidade de fragmentos homogêneos justapostos, e por heterogeneidade. Segundo a descritiva do autor, o terceiro padrão estaria mais adequado ao sentido geral de evolução das cidades. Porém é possível que os distintos padrões se apresentem na cidade, de acordo com as diferentes formas estabelecidas histórico e formais, de desenvolvimento dos territórios.

Para Krafta (2012), a urbanidade da forma não está relacionada à" aprazibilidade" dos lugares, ou ainda com animação destes lugares, mas sim com sua capacidade de mudança. A teoria do autor, particularmente nos interessa para sustentar a hipótese que os lugares provenientes das sombras dos viadutos, ou seja seus baixios, possuem urbanidade, devido à sua grande possibilidade de adaptação à utilização de diversas atividades, caracterizando-se pelo uso diverso, tanto quanto à atividades, formas e diversidade de pessoas que podem acessar estes lugares.

\section{Estratégias dos Baixios dos Viadutos}

Para verificar estratégias de ocupação, dos baixios de viadutos, na cidade de São Paulo, buscando firmar a hipótese de que estes lugares, vistos como barreiras, tem grande potencial e possuem urbanidade, buscamos, 
por meio de fotografias, perspectivas e esquemas das malhas dos lugares avaliar as relações desta urbanidade com as formas urbanas.

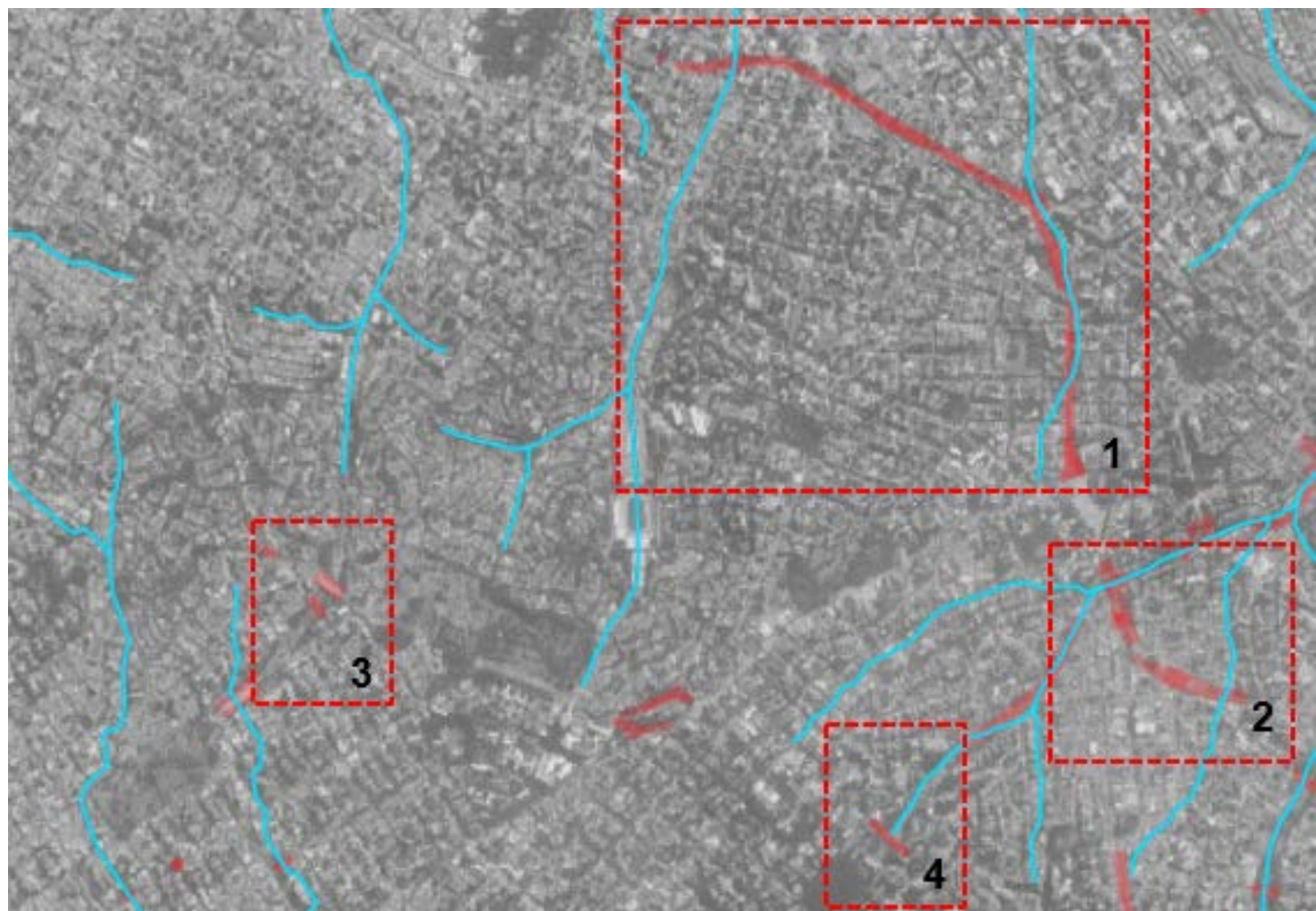

Fig. 04 Mapa com localização dos Casos avaliados. (Elaborado pela autora). 1. Viaduto Júlio de Mesquita Filho, 2. Elevado João Goulart (Minhocão), 3. Viaduto Dr. Arnaldo (Metrô Sumaré), 4. Viaduto Bernardino Tranchesi (Mirante 9 de Julho)

(1) A primeira estratégia que apresentamos, utiliza os espaços com eventos temporários, com objetivo de desenvolver vínculos afetivos com estes lugares anteriormente não utilizados. Desenvolvida pelo coletivo 'Terreyro Coreográfico' na região central da cidade de São Paulo, no bairro da Bela Vista, sob o Viaduto Júlio Mesquita Filho. O coletivo, que possui vínculo com as atividades desenvolvidas pelo Teatro Oficina, vem realizando pequenos eventos com o objetivo de descobrir possibilidades, experimentando o cotidiano dos baixios do viaduto e os modos de operar já existentes na vizinhança, o que vem garantindo um desenvolvimento crescente de atividades e o envolvimento dos diferentes agentes da região, representados pelas diferentes associações culturais e de moradores. O bairro pertence à região da Bela Vista, limitada por diferentes vias arteriais, (Paulista a Sudoeste, 23 de Maio a Leste, Nove de Julho a Noroeste e os Viadutos Júlio de Mesquita Filho e Jaceguai a Nordeste). O entorno da região do Viaduto apresenta um caráter tipológico misto com presença de edificações de um ou dois pisos, em meio a ruas estreitas, com a presença de verticalização no eixo de proximidade às Avenidas Paulista, Brigadeiro Luís Antônio e Nove de Julho. A região possui cerca de 900 imóveis catalogados e pertencentes ao cadastro do Patrimônio Histórico Cultural e Ambiental do Município e uma diversidade de atuação de agentes culturais, na presença de teatros e um eixo turístico e gastronômico, na rua Treze de Maio. 

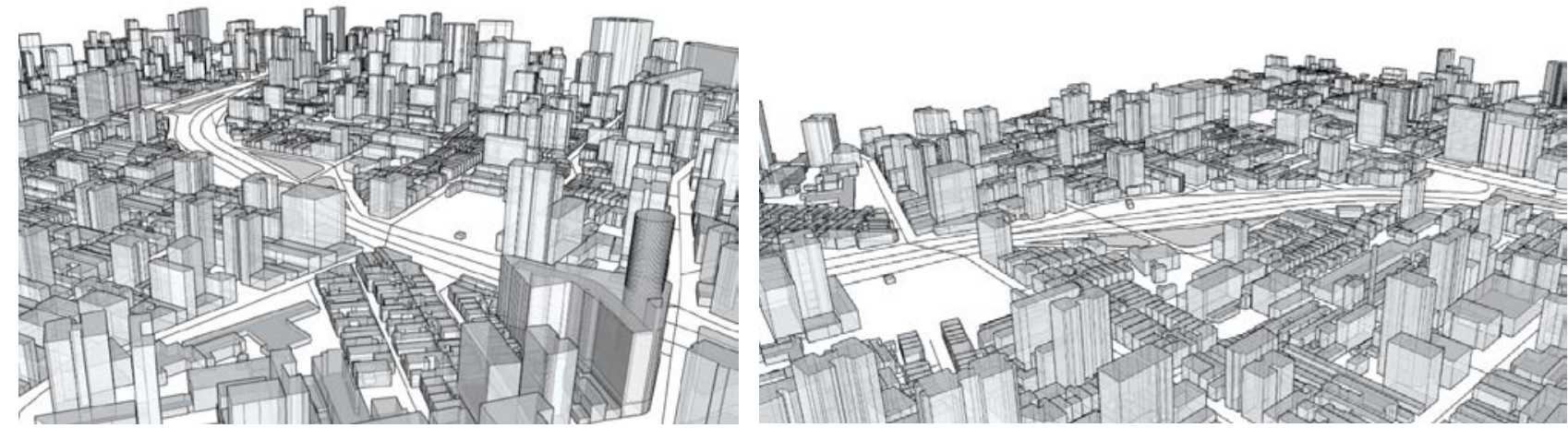

Fig. 04 e 06 Perspectivas da tipologia dos edifícios do entorno do Viaduto Júlio de Mesquita Filho. (Elaborado pela autora).
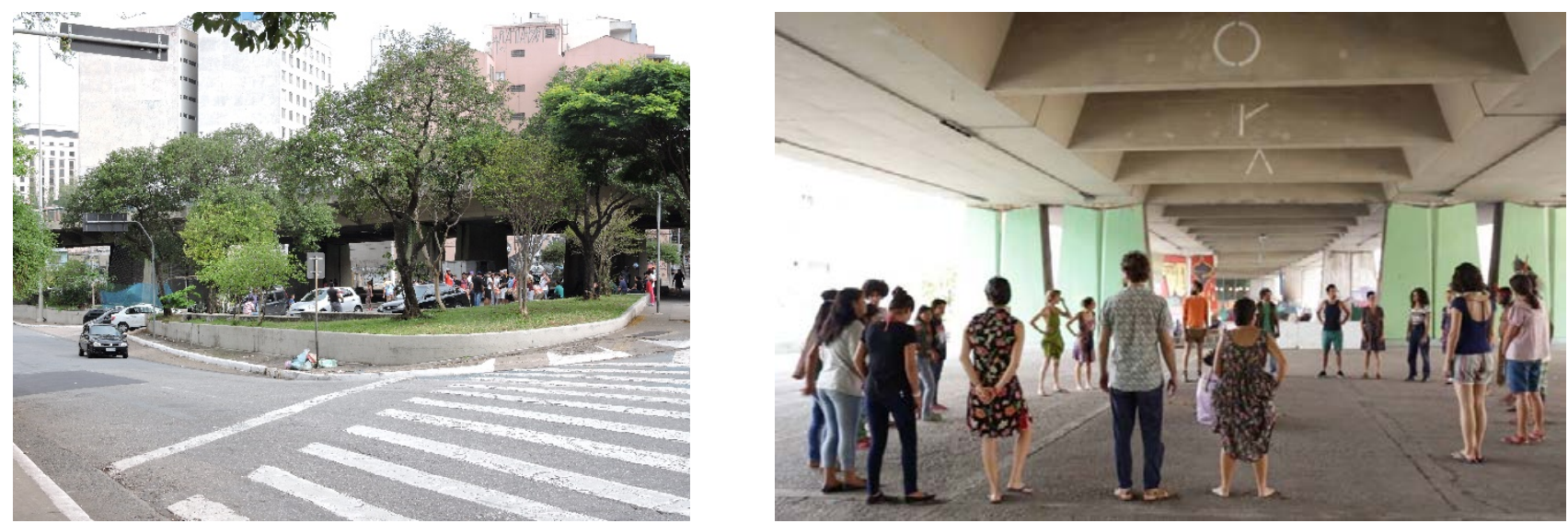

Fig. 07 e 08 Fotos dos baixios do Viaduto Júlio de Mesquita Filho. (Fontes: Autora-set.2017 e Terreyro Coreográfico. Disponível em: http://terreyrocoreografico.cc/ Acesso em Abr..2019.).

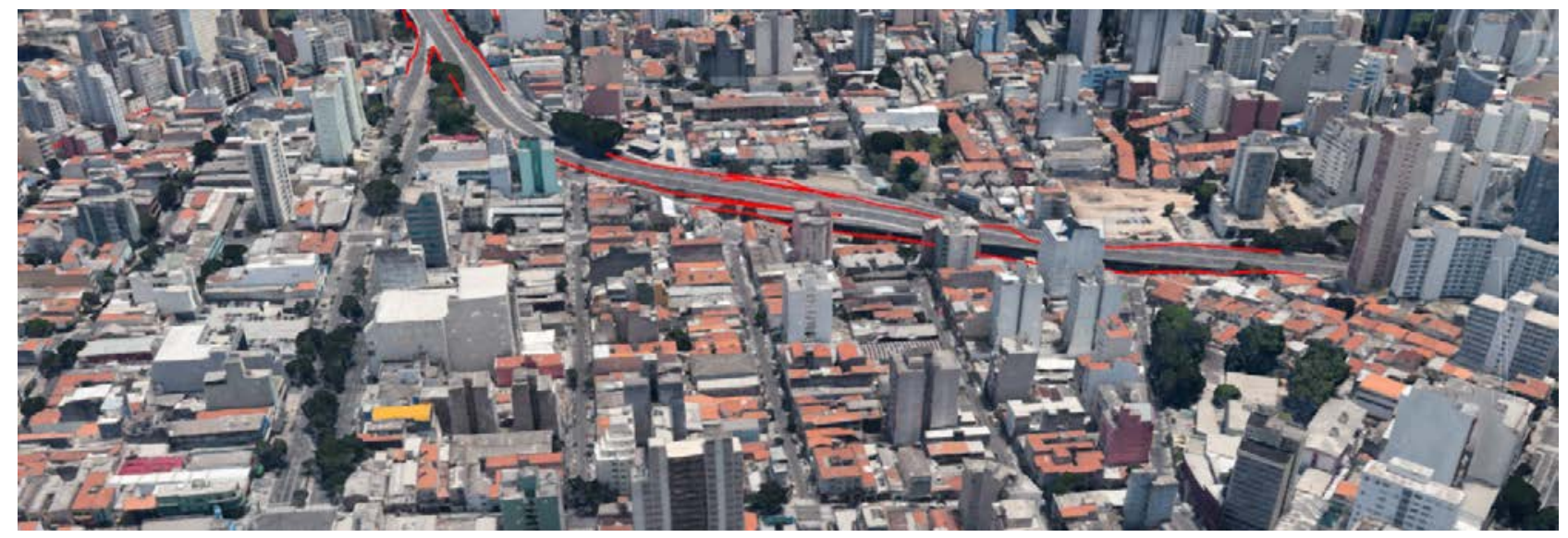

Fig. 09 Foto aérea do Viaduto Júlio de Mesquita Filho. (Fontes: Google. em: Acesso em maio.2019).

O conhecido Minhocão (atual Elevado João Goulart), pertence à mesma estrutura de deslocamento rodoviário que intercepta a cidade no eixo leste-oeste, tem características distintas dos outros viadutos, é uma estrutura elevada, que se sobrepõe à três importantes avenidas, construído no início dos anos 1970 para facilitar o deslocamento de automóveis entre as regiões da cidade. O Minhocão é visto como uma fratura de grande dimensão, suas áreas de baixios possuem dimensões modestas no eixo transversal, impostas pela proximidade dos edifícios e largura das vias às quais foram sobrepostas, porém são 3,6 km de extensão longitudinal, conectando a Praça Roosvelt à Avenida Francisco Matarazo, na zona oeste. $O$ artefato tem muitas 
apropriações, principalmente no que diz respeito ao seu tabuleiro (parte superior), nos momentos em que se abre aos pedestres e se transforma no "Parque Minhocão", em função de restrições impostas à passagem de automóveis em determinados horários do dia e da semana.

Nas áreas de seus baixios, mantém-se atividades não autorizadas pelo poder público, como o pixo e o grafitti, ou moradias informais de pessoas em situação de rua, que interferem no espaço, construindo seus abrigos, em meio à dinâmica da cidade e aos equipamentos de mobilidade, ciclovia, pontos de ônibus e estações de metrô. A região que caracteriza o entorno do artefato é caracterizada pelo comércio, sobretudo de móveis antigos, que ocupam os térreos dos edifícios lindeiros, na maioria residenciais, que configuram uma área extremamente adensada e verticalizada. Grande parcela dos imóveis foi construída antes da implantação do elevado, ou seja, entre as décadas de 1950 e 1960. As ruas possuem um traçado ortogonal configurando quadras proporcionais, dispostas de forma paralela ao sentido do Elevado.na maioria de sua extensão, alterando sua disposição e configuração conforme muda o sentido das avenidas que se situam na sua parte inferior. A região é bem servida de transportes, linha de metro e várias linhas de ônibus, além da ciclovia (Fig. 10) que percorre praticamente toda extensão inferior do Minhocão, conectando-se ao bairro dos Campos Elíseos, Pacaembú, Santa Cecília e Centro, através do Largo do Arouche (Guillén, 2016). Na mesma linha, sob a laje do Elevado, se concentram os pontos de ônibus e o terminal Amaral Gurgel, ao lado do Largo Santa Cecília.
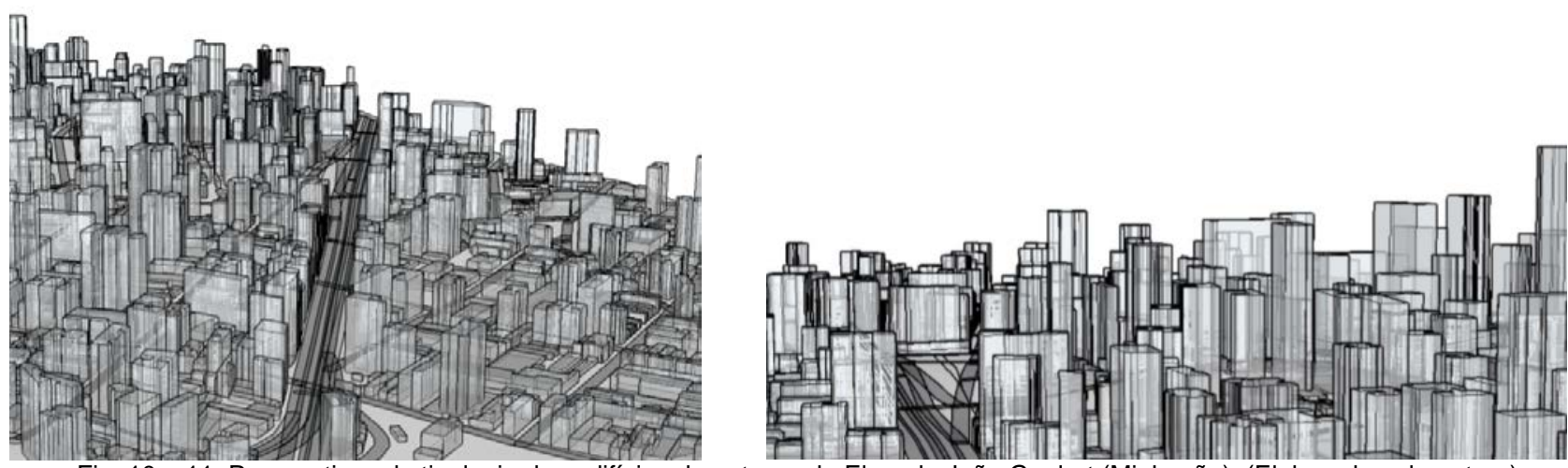

Fig. 10 e 11. Perspectivas da tipologia dos edifícios do entorno do Elevado João Goulart (Minhocão). (Elaborado pela autora).
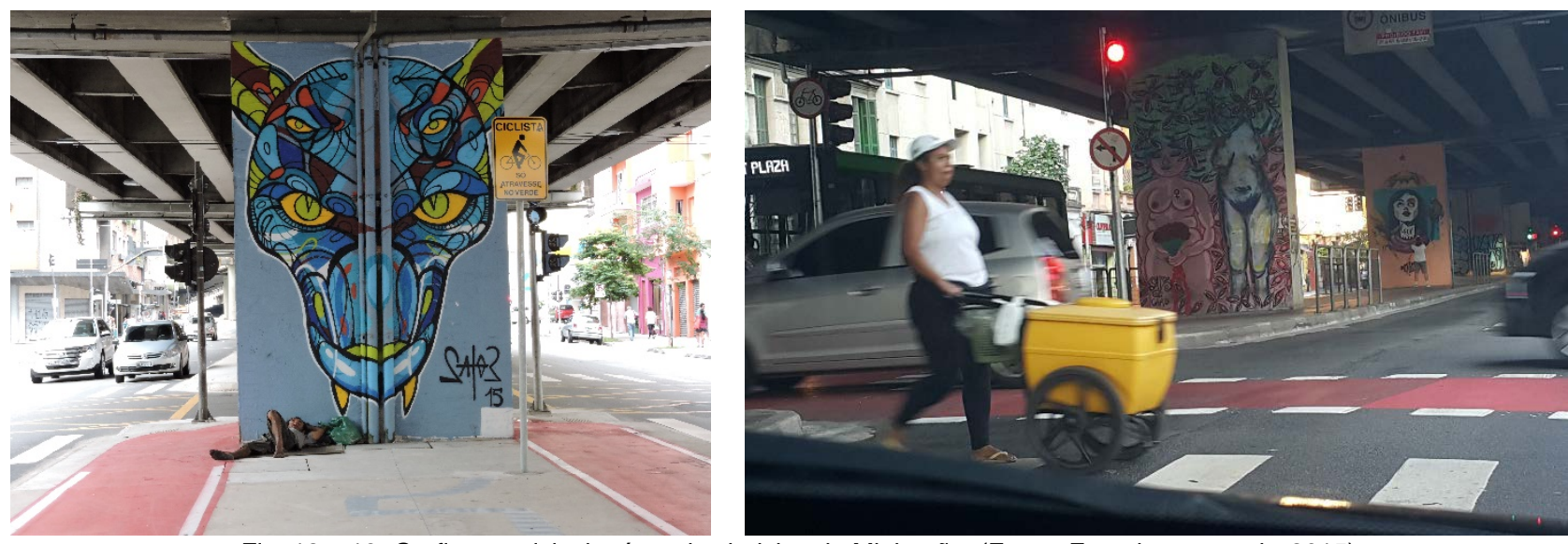

Fig. 12 e 13. Grafittes e ciclovia, área dos baixios do Minhocão. (Fonte: Foto da autora abr.2015). 

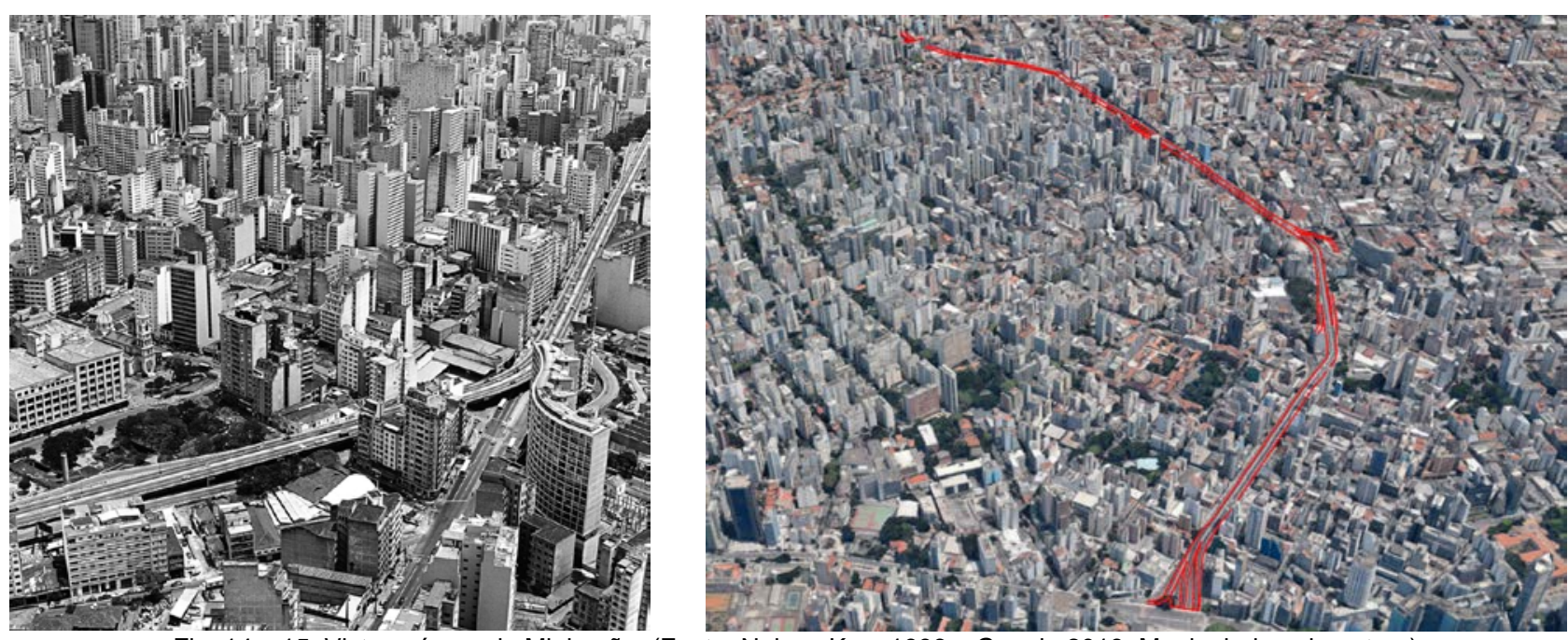

Fig. 14 e 15. Vistas aéreas do Minhocão. (Fonte: Nelson Kon, 1996 e Google 2019. Manipulado pela autora).

(2) O esporte apresenta uma alternativa para estabelecer uma apropriação nos espaços livres públicos e se configuram como espaços não construídos. Existem diferentes casos efetivados pelo poder público na cidade de São Paulo e iniciativas particulares. Casos bem-sucedidos apresentam uma identidade com as demandas da população. Na zona oeste de São Paulo, sob o viaduto da Avenida Dr. Arnaldo, sobre a Avenida Paulo VI acontece a prática do rapel, em função do desnível da altura em relação às vias. (3) Em meio às duas passagens de veículos, instalou-se a estação Sumaré, parte da terceira estratégia de apropriação dos espaços residuais observados. Pertencente a linha 2 , verde, do metrô, implantada em 1998. O viaduto e a estação de Metro Sumaré são obras de referência na cidade de São Paulo. A estação foi implantada em decorrência do traçado do terreno, um vale sem boas opções na parte subterrânea, resultando em localização privilegiada. Projeto do arquiteto Wilson Bracetti, recebeu destaque também graças à intervenção do artista plástico Alex Fleming: uma série de retratos ampliados de pessoas comuns, anônimas, tais como as que viajam nos trens, aplicados sobre o vidro. Paisagem, reflexos e rostos se fundem na alta velocidade do veículo. A solução técnica aproveitou o viaduto existente como cobertura para as plataformas e o mezanino. Os dois acessos partem de cima, do nível do viaduto, em escadarias, chegando ao pequeno mezanino, de onde se pode descortinar o amplo salão por onde passam os trens. Além da ocupação, diferente do padrão das estações paulistanas desenvolvidas até a época, o viaduto recebe também o uso da prática de rapel, em função da altura de 28 metros e das características visuais da paisagem da região. A partir da inserção de elementos construídos sob as infraestruturas, com o objetivo de programar o espaço e conferir-lhe caráter, onde os elementos construídos sob os viadutos, de acordo com uma programação resultaram não apenas em projetos de destaque, por suas articulações e propostas, como configuram permanências e grande vitalidade às áreas.

A região do Sumaré caracteriza-se por uma horizontalidade, no eixo em direção à zona noroeste, seguindo para o bairro de Perdizes, já no eixo em direção ao sudoeste, para o bairro de Pinheiros, surge a verticalização, assim como no eixo que segue em direção à Paulista. O Viaduto está inserido numa ligação de eixos, sobre vias importantes de fluxo entre as diferentes regiões, construída em fundo de vale, seguindo os córregos que surgem na região mais elevada do espigão da Avenida Paulista em direção ao Rio Tietê. 

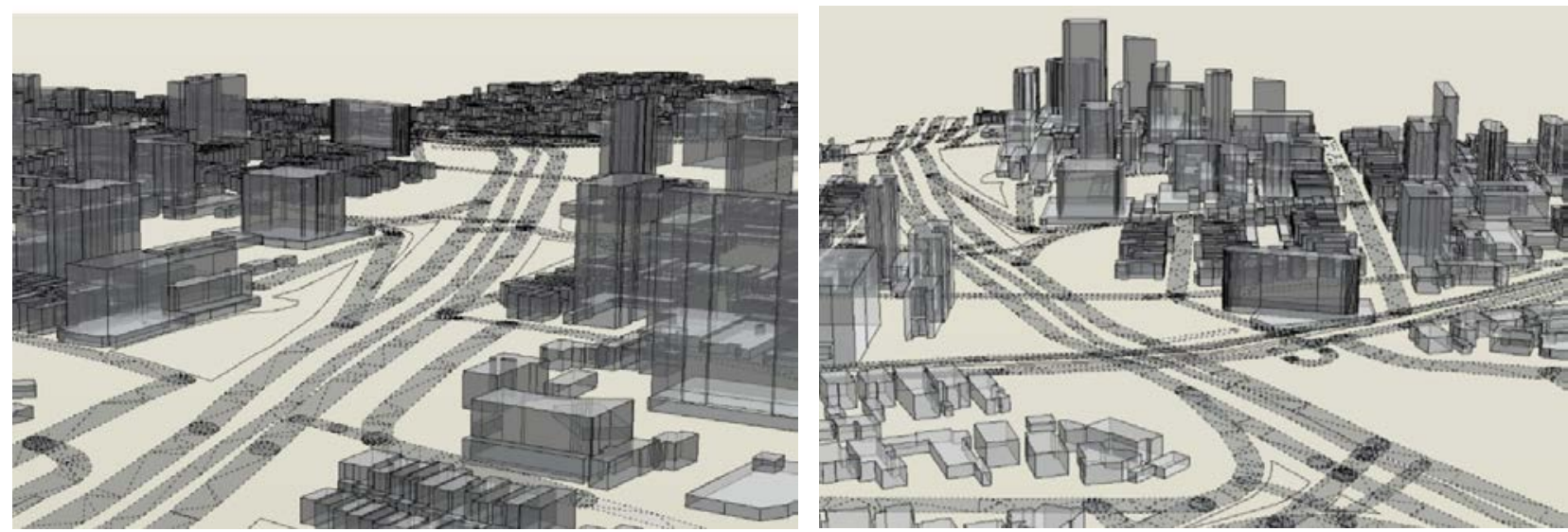

Fig. 18 e 19. Perspectivas da tipologia dos edifícios do entorno do Viaduto Metrô-Sumaré. (Elaborado pela autora)
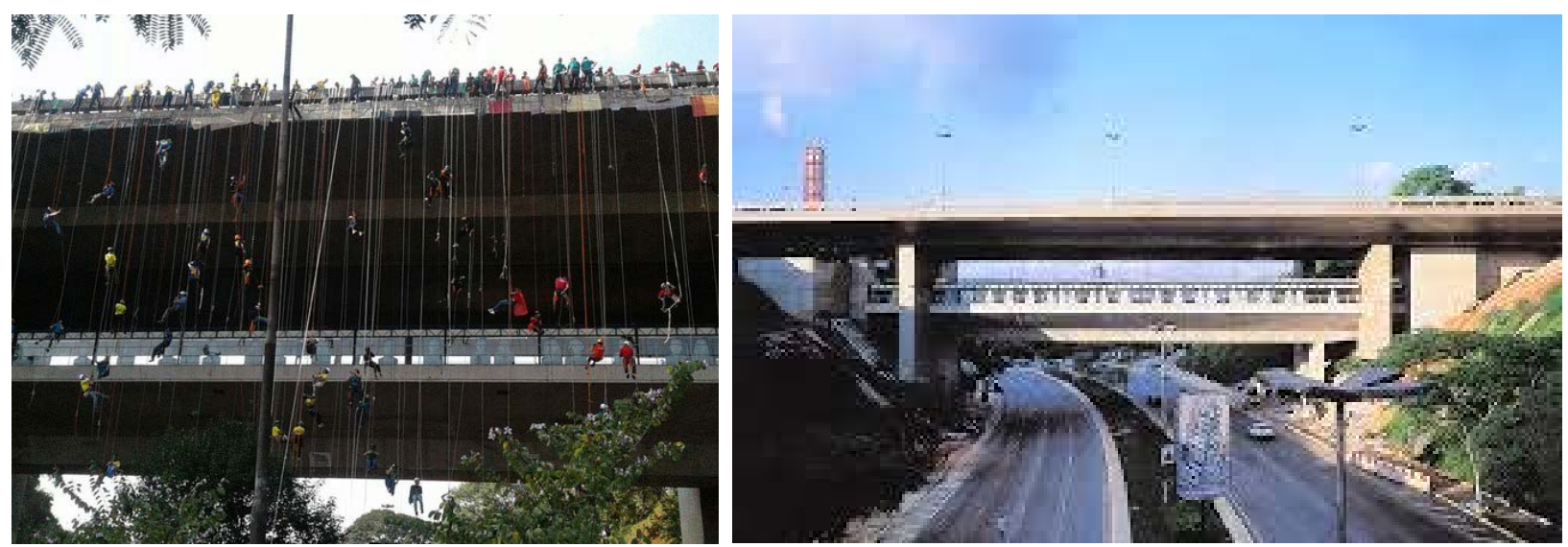

Fig. 20. Rapel no Viaduto Dr. Arnaldo-Metrô Sumaré. (Fonte: Globo. Disponível em: g1.globo.com/sao-paulo/noticia/2016/07/praticantesde-rapel-formam-simbolo-olimpico-no-viaduto-do-metro-sumare.html/ Acesso em maio/2019). Fig. 21. Vista Viaduto Metrô Sumaré. (Fonte: Setec Brasileira. Disponível em: http://www.setechidrobrasileira.com.br/en/Projetos/transporte---metroferroviario/estacaosantuario-nossa-senhora-de-fatimasumal . Acesso em maio/2019)

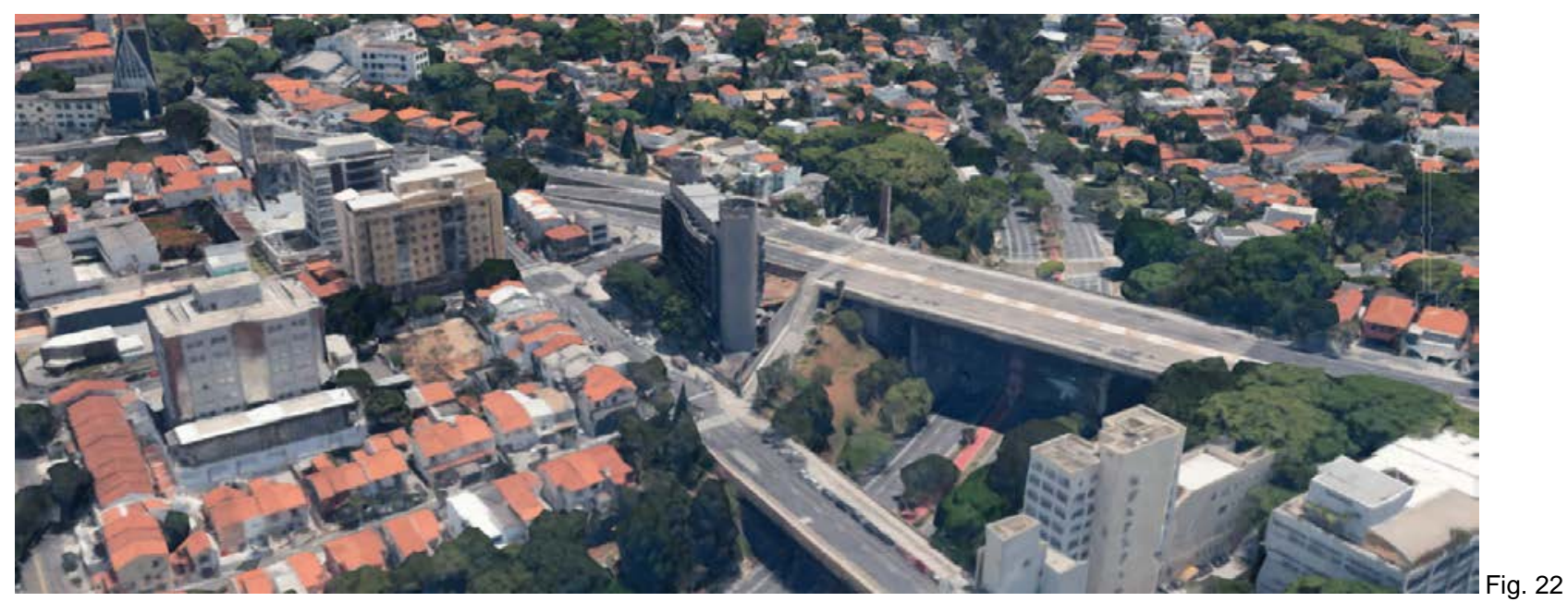

Foto aérea do Viaduto Dr. Arnaldo/ Metrô Sumaré. (Fontes: Google. em: Acesso em maio.2019).

Outro exemplo é o conhecido Mirante 9 de Julho, espaço de observação, resultado de uma fase do plano de revitalização urbanística desenvolvido para o complexo formado pelo túnel 9 de Julho e seu entorno, situado atrás do Museu de Arte de São Paulo Assis Chateaubriand (Masp), no vale que se sobrepõe à Avenida 9 de Julho e contempla a visão da parte inferior do Vão do Masp, paisagem paulistana preservada e elemento do partido do projeto de Lina Bo Bardi, para o Museu de Arte de São Paulo. Além da revitalização das áreas 
externas e do mirante situado sobre o túnel 9 de julho e sob o viaduto Professor Bernardino Tranchesi, o projeto conta com uma galeria envidraçada na laje do mirante, que é ocupada por meio de parceria com iniciativa privada, com a implantação de um bar-restaurante-galeria. O projeto arquitetônico criado pelo escritório MM18 Arquitetura, teve como premissa o respeito ao valor histórico da área, caracterizada por intervenções facilmente removíveis. A região manteve as características históricas e trouxe a possibilidade do lugar abrigar novos usos, com a exposição de filmes, shows e o desenvolvimento de diferentes eventos que se estendem em toda área pública, sob e ao redor do viaduto Bernardino Tranchesi. A região é marcada por uma malha regular com edificações de10 a 15 andares, com uma concentração de densidade nas áreas da Avenida Paulista e Avenida 9 de Julho.
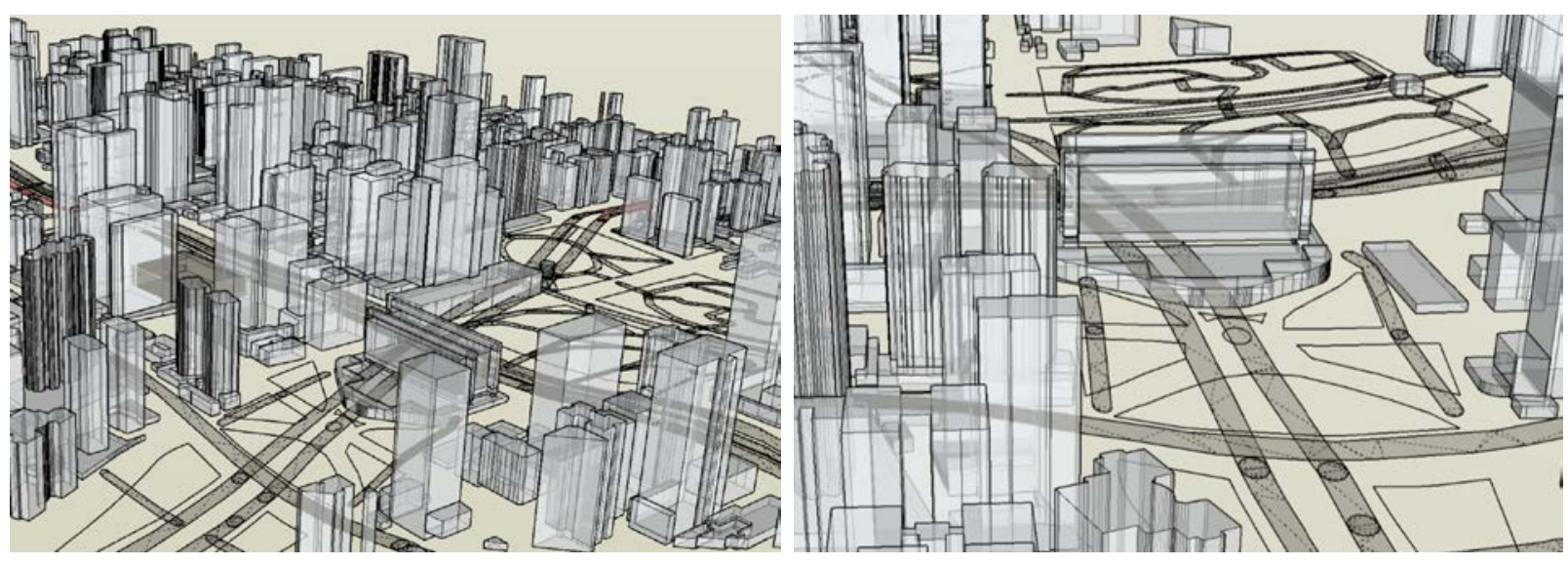

Fig. 23 e 24. Perspectivas da tipologia dos edifícios do entorno do Mirante 9 de Julho. (Elaborado pela autora).
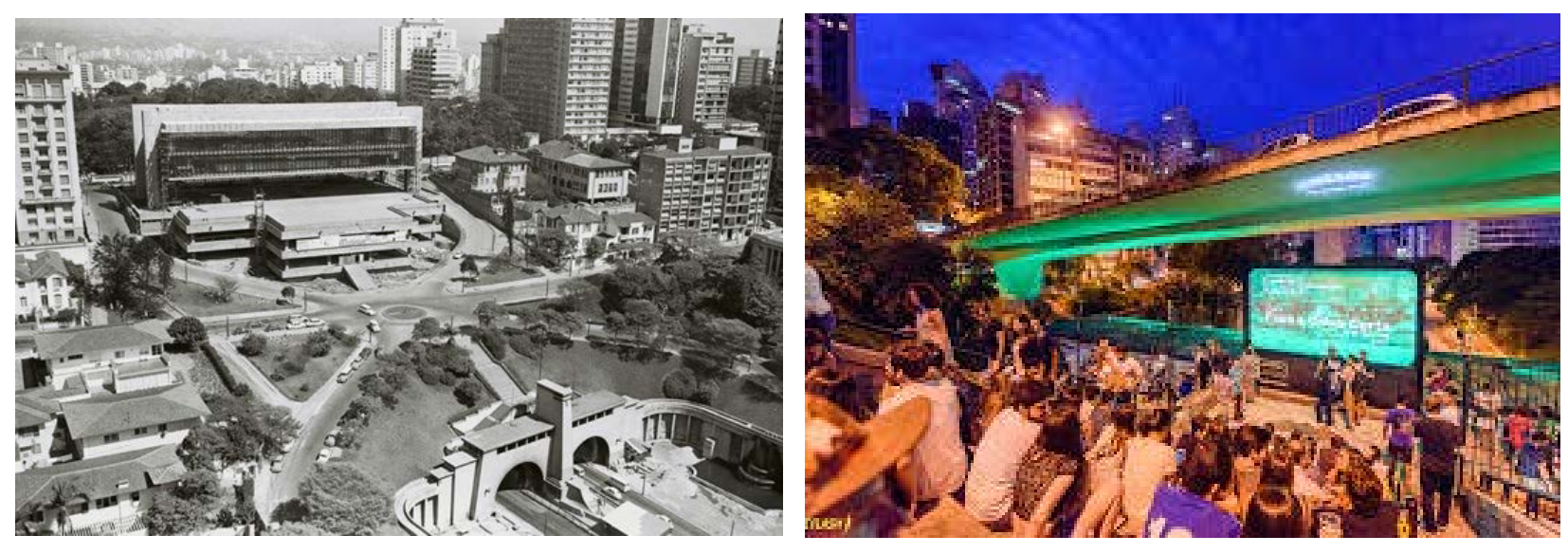

Fig. 25. Masp e Mirante 9 de Julho antes do Viaduto. (Fonte:Arcoweb. Disponível em:

https://www.arcoweb.com.br/noticias/arquitetura/mm18-arquitetura-mirante-9-de-julho-sao-paulo Acesso em maio/2019). Fig. 26. Vista Viaduto Metrô Sumaré. (Fonte: Ag.Jornalismo. Disponível em: http://ag.jor.br/blog/2016/08/15/mirante-9-de-julho-exploracao-privada-doespaco-publico/ Acesso em maio/2019) 


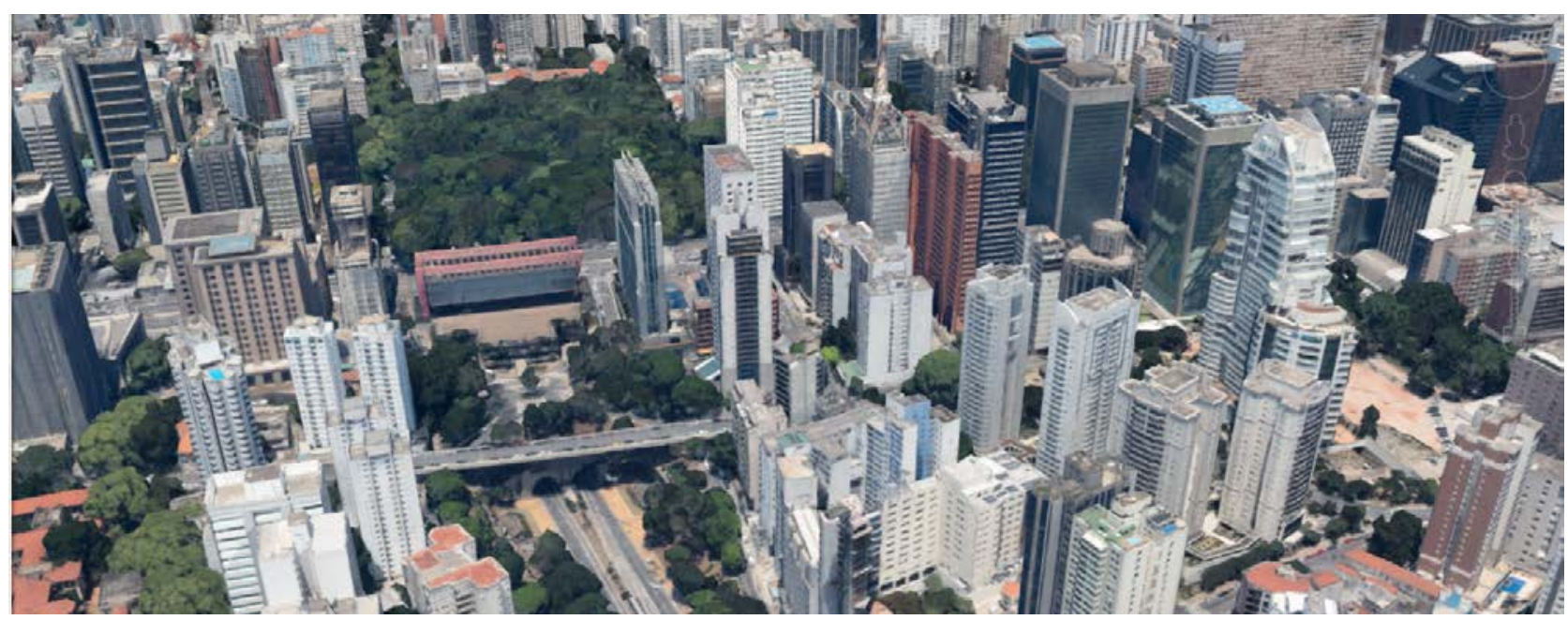

Fig. 27 Foto aérea do Mirante 9 de Julho/ Masp e Av. 9 de Julho. (Fontes: Google. em: Acesso em maio.2019).

\section{Resultados}

A cidade de São Paulo, por sua complexidade espacial, nas dimensões geográficas e morfológicas de seu território, assim como por sua diversidade social, estabelece a imagem que a urbanidade e segregação espacial sejam fenômenos qualitativamente opostos, ainda que resultantes de um mesmo conjunto. (AGUIAR, 2012). Visualizar a articulação destes espaços, como espaços públicos, constitui a dimensão sintática da cidade que se refere, por um lado, à relação destes entre si - ruas, avenidas etc. e, por outro, ao modo como se relacionam com as edificações que os constituem, que os conformam.

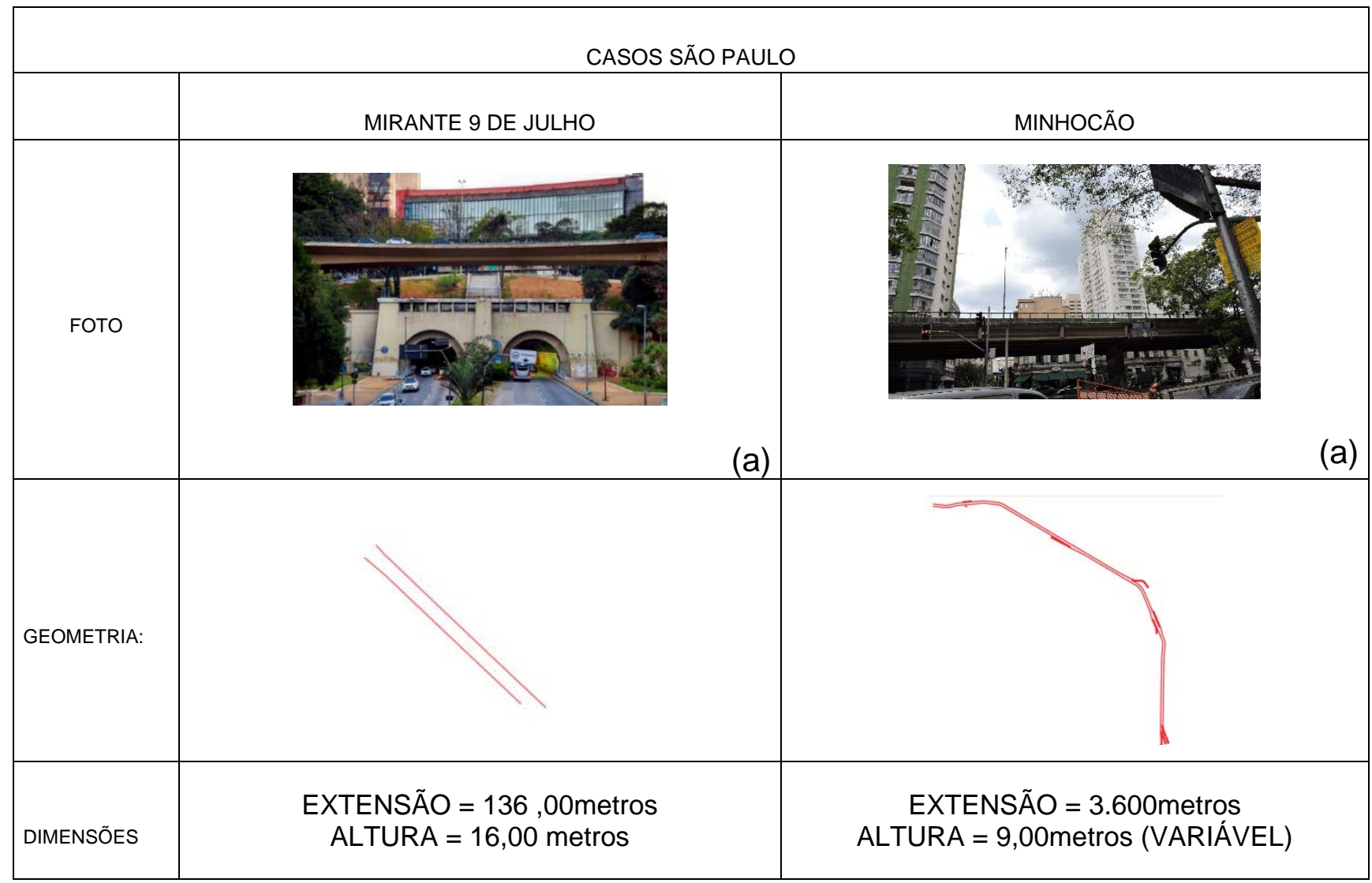




\begin{tabular}{|c|c|c|}
\hline MALHA: & (b) & (b) \\
\hline TIPOLOGIAS: & $\begin{array}{l}\text { VERTICAL COM MUITA DENSIDADE E DIVERSIDADE } \\
\text { DE USOS. LOCAL JUNTO AO VIADUTO COM VISÃO } \\
\text { PRESERVADA - MIRANTE HISTÓRICO-TURÍSTICO }\end{array}$ & $\begin{array}{c}\text { VERTICAL - RESIDENCIAL COM COMERCIO NO } \\
\text { TÉRREO. PRESENÇA DOS PRINCIPAIS MODAIS DE } \\
\text { TRANSPORTE PÚBLICO }\end{array}$ \\
\hline ESTRATÉGIAS: & ESPAÇO PROGRAMÁTICO E EVENTOS & ARTE URBANA / MOBILIDADE \\
\hline FONTES: & $\begin{array}{l}\text { Fonte:(a) https://www.arcoweb.com.br/noticias/arquitetura/mm18- } \\
\text { arquitetura-mirante-9-de-julho-sao-paulo. Acesso em maio/19; } \\
\text { (b)Mmapa QGIS, manipulação autora }\end{array}$ & $\begin{array}{l}\text { Fonte: (a) Foto da autora. Abr.2015; (b)Mapa QGIS, manipulação } \\
\text { autora }\end{array}$ \\
\hline
\end{tabular}

Tab. 02 Análise dos Casos: Baixios de Viadutos em São Paulo. (Elaboração da autora)

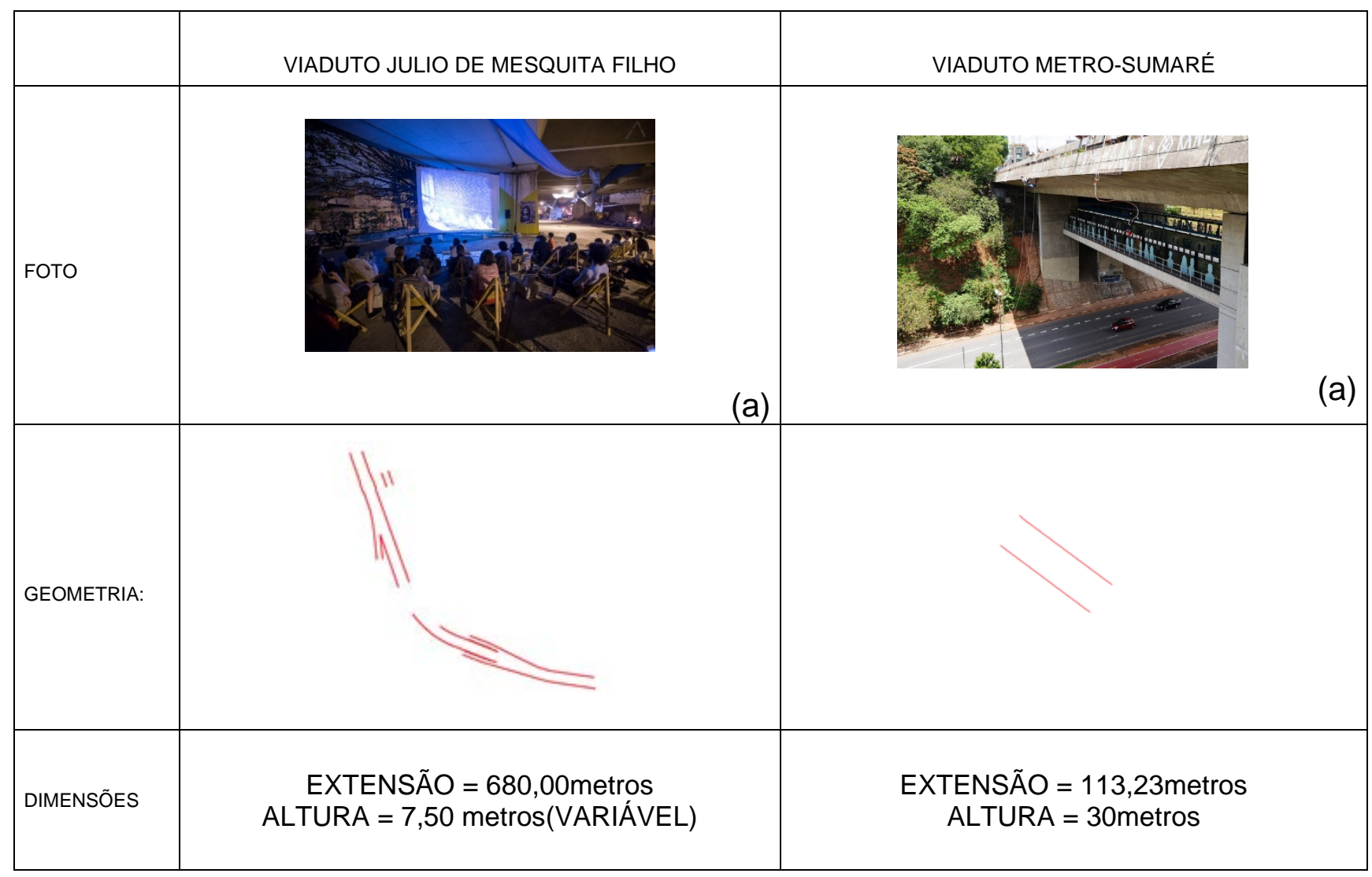




\begin{tabular}{|c|c|c|}
\hline MALHA: & (b) & (b) \\
\hline TIPOLOGIAS: & $\begin{array}{c}\text { HORIZONTAL DE ATE DOIS ANDARES COM PRESENÇA } \\
\text { DE VERTICALIZAÇÃO JUNTO AS PRINCIPAIS VIAS DO } \\
\text { BAIRRO. A REGIÃO JUNTO AO VIADUTO TEM } \\
\text { CONCENTRAÇÃO DE RESIDÊNCIAS E ESPAÇOS } \\
\text { CULTURAIS (TEATROS) }\end{array}$ & $\begin{array}{c}\text { HORIZONTAL NA PORÇÃO NOROESTE E VERTICAL } \\
\text { NA SUDOESTE. EIXO DO VIADUTO SOBRE A VIA COM } \\
\text { GRANDE DESNÍVEL E VISTA PRIVILEGIADA DAS } \\
\text { REGIÕES DO ENTORNO. MODAL DE TRANSPORTE } \\
\text { PÚBLICO ANEXO AO VIADUTO }\end{array}$ \\
\hline ESTRATÉGIAS: & ESPAÇO PROGRAMÁTICO & ESPAÇO PROGRAMÁTICO / ESPORTES \\
\hline FONTES: & $\begin{array}{l}\text { Fonte:(a) http://terreyrocoreografico.cc/ (b)Mmapa QGIS, } \\
\text { manipulação autora }\end{array}$ & $\begin{array}{l}\text { Fonte:(a) } \\
\text { http://www.setechidrobrasileira.com.br/port/Projetos/trans } \\
\text { porte---metroferroviario/estacao-santuario-nossa-senhora- } \\
\text { de-fatimasuma. (acesso em 21/02/2019). (b)Mmapa } \\
\text { QGIS, manipulação autora }\end{array}$ \\
\hline
\end{tabular}

Tab. 03 Análise dos Casos: Baixios de Viadutos em São Paulo. (Elaboração da autora)

Visualizamos grande potencial de urbanidade nestes cenários, embora sejam recorrentes paisagens de degradação e descaso do poder público, estabelecendo barreiras, não apenas físicas, mas também sociais. Esta condição se apresenta frente a vivência dos habitantes da região, manifestada pela influência da cultura do bairro, como modo de vida, presente e atuante no cotidiano e no imaginário coletivo, assim como pelo estabelecimento de uma vitalidade local, que potencializa a ocupação das pessoas naquele espaço público, o que caracteriza, de acordo com Tschumi (1994), 'o lugar onde espaços e ações que se confrontam'.

Os casos de São Paulo possuem dinâmicas distintas, com territórios estabelecidos em situações geográficas e sociais diferentes, o que nos leva a refletir que não é apenas a presença de dinâmicas projetuais e de ocupação que estabelece o atributo da urbanidade, mas também os aspectos ligados à materialidade e espacialidade, assim como as características sociais e econômicas que envolvem o entorno dos espaços.

As estratégias de ocupação dos espaços nos baixios dos viadutos em São Paulo, fruto da análise aqui proposta, revelam possibilidades tanto de, como o caso do Viaduto Júlio de Mesquita Filho. Os lugares podem receber novos usos e estabelecer diferentes relações com o entorno, tanto com atividades transitórias ou com aquelas de caráter permanente. Percebe-se que mesmo os espaços programáticos, fruto de projetos de intervenção arquitetônica, não são capazes, sozinhos de estabelecer uma ativação destes lugares, são necessárias atividades em conjunto para estabelecer um nível de vitalidade que possa qualificar estes espaços. Características como a topografia, no caso dos Viadutos do Metrô Sumaré e do Mirante 9 de julho, agregam maior valor aos projetos, assim como características do local, que possibilitam o desenvolvimento de atividades distintas dos outros casos, instalados em vales, sob as vias, casos do Viaduto Julio Mesquita e Minhocão. As atividades que se manifestam nos quatro casos apresentados tem suas presenças ancoradas no cotidiano e nas dinâmicas dos usuários do entorno, seja porque se manifestam como lazer e ócio (Rapel do Viaduto Sumaré) ou atratores turísticos (Mirante 9 de Julho), marcos na paisagem paulistana (Metrô Sumaré e 
Minhocão) ou como locais onde o encontro e a manifestação cultural permite transbordar os limites impostos por arquiteturas, como o caso das ocupações das atividades do e do Terreyro Coreográfico, ligado ao Teatro Oficina, projeto de Lina Bo Bardi ${ }^{1}$

A configuração da malha do traçado urbano, que intercepta estes locais, provenientes da implantação de vias urbanas, evidencia o passado e os resultantes impostos pelo tempo, os espaços que permanecem e recebem novas configurações, a partir de novos elementos, como o Mirante 9 de Julho que contempla uma paisagem histórica preservada, ou de novas visões a partir de transposições criadas como o Metrô Sumaré, uma estrutura realizada anos após a implantação do Viaduto da Avenida Dr. Arnaldo. O Viaduto Júlio de Mesquita Filho denuncia a ruptura da malha do bairro da Bela Vista, restringindo as passagens e a permeabilidade do bairro, no vale onde antes corria o córrego. É possível imaginar, porém, em todos os casos, por meio das atividades elencadas, algum tipo de liga, de sutura, que possa ser responsável por cerzir o território, rompido pela circulação dos automóveis.

A dicotomia, presente nas passagens subterrâneas do Minhocão, revela a arte urbana, que toma emprestado o suporte de concreto do artefato urbano para imprimir seu caráter subversivo e sua linguagem de confronto. As camadas sobrepostas das intervenções artísticas se mesclam às porções segregadas das avenidas inferiores ao elevado, com tipologias edilícias distintas, temporalidades e usos distintos.

A presença da urbanidade pode ser observada de diferentes formas nos casos apresentados, de acordo com as percepções diferentes que enunciam suas dimensões geométricas, os maiores são o Minhocão e Julio de Mesquita Filho e a presença da dimensão livre e vista do horizonte da cidade, presentes nos casos do Viaduto do Metrô Sumaré e Mirante 9 de Julho. As presenças das transformações históricas são mais evidentes nos casos no Minhocão e do Júlio de Mesquita, que impões diferenças nos territórios que rompem já as alterações históricas impostas pela canalização dos cursos de água e o surgimento dos viadutos nos outros casos não causa tanto impacto.

As teorias da urbanidade defendidas por Krafta (2012), são observadas nos casos apresentados, no que se refere ao exame das características dos objetos da cidade à luz das pré-existências, assumindo que as ações de produção e intervenção nos territórios pressupõem códigos de urbanidade.

\section{BIBLIOGRAFÍA}

AGUIAR, D. e NETTO, V. M. (2012). Urbanidades. Rio de Janeiro: Folio Digital/Letra e Imagem. Disponível em: https://www.academia.edu/6314921/URBANIDADES. Livro completo. Acesso em abr.2019

CAMPOS, C.M. (2008). Eixo da Ambiguidade: a região da Avenida São João nas inversões do tempo. In: ARTIGAS, R. e MELLO, J.e CASTRO, A.C. Caminhos do Elevado: Memórias e Projetos. São Paulo. Imprensa Oficial do Estado de São Paulo.

FOUCAULT, M. (1984). O corpo utópico, as heterotopias. Posfácio de Daniel Defert. [tradução Salma Tannus Muchail]. São Paulo.

GUATELLI, I. (2008). Condensadores Urbanos: Baixio Viaduto do Café - Academia Cora-Garrido. São Paulo: Instituto Presbiteriano Mackenzie.

GUATELLI, I. (2012). O(s) lugar(es) do Entre na Arquitetura Contemporânea (Arquitetura e pós-estruturalismo francês). Tese (Doutorado) - Faculdade de Filosofia, Letras e Ciências Humanas, Universidade de São Paulo. São Paulo.

1 Teatro Oficina: Projeto de Lina Bo Bardi e Edson Elito, em 1991, inaugurado em 1993 
GUILLÉN, M. I. C. (2016). Sob [re] o minhocão: apropriações, arte e festa. 187 fls. Dissertação de Mestrado (Arquitetura e Urbanismo) - Universidade Presbiteriana Mackenzie, São Paulo.

HAUCK, T., KELLER, R. e KLEINEKORT, V (ed.). (2011). Infrastructural urbanism: addressing the in-between. Berlin: DOM Publishers.

HILLIER, B. (1989). The architecture of the urban object. Ekistics, v. 56, n. 334/33, p. 5-21.

HOLANDA ET al. (2003). Arquitetura e Urbanidade. São Paulo: Pro Editores.

JACOBS, J. (1960). Morte e vida de grandes cidades. $3^{\text {a }}$ edição. São Paulo: Martins.

KRAFTA, R, NETTO, V e LIMA, L. (2010). Urban Built Form Grows Critical, Proceedings of the European Conference on Complex Systems, Lisbon, ECSS.

KRAFTA, R. (2012). Impressões da Urbanidade. In book: Urbanidades. Publisher: Folio Digital. Editors: Douglas Vieira de Aguiar, Vinicius M. Netto.

KROPF, K., CONZEN, M.R.G. e CANIGGIA, G. (2004). Oscar Wilde and Aesop: Or, why urban morphology may be right but not popular. Urban Morphology. Vol 8.

LEFEBVRE, H. (1974). La producción del espacio. Revista de Sociología, [S.I.], v. 3, p. 219-229. ISSN 20139004. Disponible en: <https://papers.uab.cat/article/view/v3-lefebvre>. Acceso: 10 mayo/ 2019 Disponible en: doi:http://dx.doi.org/10.5565/rev/papers/v3n0.880.

LYNCH, K. (1961). A imagem da cidade. São Paulo: Martins Fontes.

MAGRINYÀ, F. (1999). Urbanisme de les xarxes: instrument de lectura de l'ecosistema urbà. En: Rueda, Salvador. La ciutat sostenible: un procés de transformació. Girona: Universitat de Girona.

SOLÀ-MORALES, M. (2008). De cosas urbanas. Gustavo Gili, Barcelona.

TSCHUMI, B. (1994). Architecture and Disjunction. Cambridge, Mass: MIT Press, p.121-140.

\section{Periódicos:}

CLUA, A. (2017). Underground urbanity: from the carrefour à étages multiples to the 'inner street. VLC Arquitectura, Vol. 4, Issue 1, p.61-95. ISSN: 2341-3050. Access in May/2019. Available in:https://doi.org/10.4995/vlc.2016.6963 